\title{
Lipids profile among ART-naïve HIV infected patients and men who have sex with men in China: a case control study
}

Qi Wang ${ }^{1,2+}$, Haibo Ding ${ }^{1,2}$, Junjie Xu ${ }^{1,2}$, Wenqing Geng ${ }^{1,2}$, Jing Liu ${ }^{1,2}$, Xiaolin Guo ${ }^{1,2}$, Jing Kang ${ }^{1,2}$, Xiaolin Li $i^{1,2}$, Yongjun Jiang ${ }^{1,2}$ and Hong Shang ${ }^{1,2^{*}+}$

\begin{abstract}
Background: Dyslipidemia is commonly seen in human immunodeficiency virus (HIV) infected patients. Understanding the risk factors of abnormal lipid profiles is urgent for proposing targeted approaches to prevention. Our objective was to assess the incidence and associated factors of abnormal lipid profiles and atherogenic index of plasma (AIP) among antiretroviral therapy (ART) naïve men who have sex with men (MSM) acute HIV infection (AHI) and chronic HIV infection (CHI) patients in China.
\end{abstract}

Methods: We compared lipids parameters such as triglycerides (TG), low-density lipoprotein cholesterol (LDL-C), total cholesterol (TC), high-density lipoprotein cholesterol (HDL-C) and AIP between MSM HIV-infected patients and MSM HIV negative controls. Multivariable linear regression was used to evaluate risk factors of higher AIP.

Results: We performed a case control analysis of $110 \mathrm{AHI}, 110 \mathrm{CHI}$ and $100 \mathrm{HIV}$ negative MSM participants. The TC, $\mathrm{HDL}-\mathrm{C}$ and LDL-C levels were decreased in the $\mathrm{AHI}$ and $\mathrm{CHI}$ groups compared to the controls $(3.90 \pm 0.73 \mathrm{mmol} / \mathrm{L}$ and $3.72 \pm 0.74 \mathrm{mmol} / \mathrm{L}$ versus $4.49 \pm 0.91 \mathrm{mmol} / \mathrm{L}, p<0.001 ; 1.00 \pm 0.25 \mathrm{mmol} / \mathrm{L}$ and $1.01 \pm 0.30 \mathrm{mmol} / \mathrm{L}$ versus $1.19 \pm$ $0.29 \mathrm{mmol} / \mathrm{L}, p<0.001 ; 2.11 \pm 0.57 \mathrm{mmol} / \mathrm{L}$ and $2.22 \pm 0.58 \mathrm{mmol} / \mathrm{L}$ versus $2.75 \pm 0.78 \mathrm{mmol} / \mathrm{L}, p<0.001)$. The AIP score was higher in the AHI patients compared to the control group [0.08 $(-0.05-0.20)$ versus $-0.04(-0.21-0.22), p=0.039]$. In total groups, AIP was associated with AHI and TG positively $(\beta=0.029 \pm 0.012, p=0.015 ; \beta=0.273 \pm 0.009, p<0.001)$ and correlated with $\mathrm{HDL}-\mathrm{C}$ inversely $(\beta=-0.444 \pm 0.023, p<0.001)$.

Conclusions: HIV infection contributed to decreased TC, LDL-C and HDL-C. AHI contributed to higher AIP level. An urgent need exists for earlier HIV diagnosis and better prevention of dyslipidemia in China.

Keywords: Human immunodeficiency virus (HIV), Atherogenic index of plasma (AIP), Lipids, Dyslipidemia

Abbreviations: AHI, Acute human immunodeficiency virus infection; AIDS, Acquired immune deficiency syndrome; AIP, Atherogenic index of plasma; ART, Antiretroviral therapy; BMI, Body mass index; CHI, Chronic human immunodeficiency virus infection; DBP, Diastolic blood pressure; FBG, Fasting blood glucose; HDL-C, High-density lipoprotein cholesterol; HIV, Human immunodeficiency virus; IQR, Interquartile range; LDL-C, Low-density lipoprotein cholesterol; MSM, Men who have sex with men; SBP, Systolic blood pressure; SD, Standard deviation; TC, Total cholesterol; TG, Triglycerides; VCT, Voluntary counseling and testing; WHO, World Health Organization

\footnotetext{
* Correspondence: hongshang100@hotmail.com

${ }^{\dagger}$ Equal contributors

${ }^{1}$ Key Laboratory of AIDS Immunology of National Health and Family Planning

Commission, Department of Laboratory Medicine, The First Affiliated

Hospital, China Medical University, Shenyang, Liaoning 110001, People's

Republic of China

${ }^{2}$ Collaborative Innovation Center for Diagnosis and Treatment of Infectious

Diseases, Hangzhou, China
}

(c) 2016 The Author(s). Open Access This article is distributed under the terms of the Creative Commons Attribution 4.0 International License (http://creativecommons.org/licenses/by/4.0/), which permits unrestricted use, distribution, and reproduction in any medium, provided you give appropriate credit to the original author(s) and the source, provide a link to the Creative Commons license, and indicate if changes were made. The Creative Commons Public Domain Dedication waiver (http://creativecommons.org/publicdomain/zero/1.0/) applies to the data made available in this article, unless otherwise stated. 


\section{Background}

As a kind of metabolic abnormalities, dyslipidemia has been of significant concern among human immunodeficiency virus (HIV) infected patients [1-3]. HIV-infected adults with lipids perturbations may be at risk of accelerated atherosclerosis and cardiovascular disease [4]. Various lipid abnormalities have been recorded in HIV patients with antiretroviral therapy (ART), particularly those on protease inhibitors based regimes $[5,6]$. The dyslipidemia associated with ART is manifested as increased trigylcerides (TG), low-density lipoprotein cholesterol (LDL-C), total cholesterol (TC) and lower highdensity lipoprotein cholesterol (HDL-C) typically $[7,8]$.

Recently, the effect of HIV itself has been proposed as a contributor to lipid abnormalities. HIV infection may lead to structural and functional changes in HDL-C [9]. In both ART-naïve chronic HIV infection (CHI) adult and children patients, low HDL-C was the most frequently observed abnormality and there existed a significant relationship between lipid parameters and viral load $[10,11]$. Results from the Veterans Aging Cohort Study showed that HIV infection was associated with decreased TC, HDL-C, LDL-C and elevation of TG, ART initiation did not reverse alteration in TG or LDL-C to pre-HIV infection levels [12]. This suggests that HIV infection may influence lipids regardless of ART status. Furthermore, experiment in vitro demonstrated that the high viremia levels of acute HIV infection (AHI) impaired cholesterol efflux capacity, which indicated that dyslipidemia may occur very early [13].

However, relying solely on single lipid parameter is not sufficient for evaluating lipid metabolism. Attentions should be paid to more sensitive indexes. The atherogenic index of plasma (AIP) $[\log (\mathrm{TG} / \mathrm{HDL}-\mathrm{C})]$, which correlates well with the size of HDL-C and LDL-C particles, reflects the presence of atherogenic small particles accurately [14]. AIP is scarcely taken into consideration in studies which investigating lipid profiles in HIV patients. In recent years, men who have sex with men (MSM) have been a major core risk population for HIV epidemic in China [15]. Moreover, some traditional risk factors for dyslipidemia such as smoking, alcohol, abnormal nutritional status, and recreational drug use were more likely to be prevalent among MSM $[16,17]$. Thus, we hypothesize that the proportion of abnormal lipid profiles in ART-naïve MSM HIV patients in China is high and may occur very early.

Therefore, we investigated the condition of lipid metabolism and AIP among AHI and CHI ART-naïve MSM populations in China without the confounding factor of ART with a well matched HIV negative MSM group. Furthermore, we aimed to investigate the contribution of HIV to lipid abnormalities and associated factors influencing AIP in ART-naïve patients in China.

\section{Methods}

\section{Study design and participants}

This was a cross-sectional study carried out at the acquired immune deficiency syndrome (AIDS) clinical care centre of The First Affiliated Hospital of China Medical University and the Beijing You'An Hospital from January 2013 to June 2015 consecutively. Every 4-8 weeks, 6000 individuals from the HIV primary open cohort in Beijing and 1650 volunteers recruited from the Rainbow Harbor voluntary counseling and testing (VCT) Center in the First Affiliated Hospital of China Medical University in Shenyang were tested for AHI. The plasmas were collected and tested for HIV antibodies and HIV viral load. Participants were classified as AHI who met 1 of 2 criteria: (1) had negative or uncertain HIV serology with HIV RNA more than 10,000 copies/ml or (2) had a positive HIV serology with evidence of negative testing in the previous 6 months. Other volunteers who were HIV negative were invited in the control group (no-HIV group). The inclusion criteria for the no-HIV group were (a) male, self-reporting anal intercourse with male partners in the past 1 year, (b) aged 18 years or older. Eligibility criterion for the CHI group was positive HIV antibody confirmed by Western blot test for more than 6 months.

Exclusion criteria for the three groups were suffering with severe respiratory failure, kidney failure, heart failure (New York class III or IV), chronic alcoholism, cachexia status, diabetes, taking medicines of steroid hormones or lipid-lowing drugs at the study recruitment period. The study was approved by the Ethics Committee of the First Affiliated Hospital of China Medical University and the Beijing You'An Hospital. All participants provided written informed consent before attending this study.

\section{Data collection}

Data regarding sociodemographic characteristics, including gender, age, height, weight, smoking, alcohol consumption were recorded through a interviewer filled questionnaire which administered face to face in a private counseling room. The body mass index (BMI) was calculated using the formula of weight $(\mathrm{kg}) /$ height $\left(\mathrm{m}^{2}\right)^{*} 10000$.

Venous blood was drawn by trained nurses. Serum samples were tested for HIV antibody screening using a thirdgeneration enzyme-linked immunosorbent assay. Samples with positive screening test result were confirmed by HIV$1 / 2$ Western blot assay. We used the whole blood samples to determine the counts and percentages of CD4 + T cells and $\mathrm{CD} 8+\mathrm{T}$ cells by a FACS Calibur flow cytometer (Becton-Dickinson, USA). Plasma HIV viral load was detected by Roche COBAS TaqMan.

The blood pressure was measured by a sphygmomanometer with the patient sitting quietly. The systolic blood pressure (SBP) is equivalent to the value of mercury column 
when hearing the first sound of artery pulse. When the artery pulse sound decreased or disappeared, the reading of the mercury column is the value of diastolic blood pressure (DBP). The blood pressure was measured twice at least 5 min apart. The mean value of two results was recorded. Hypertension was defined as $\mathrm{SBP} \geqq 140 \mathrm{mmHg}$ and/or $\mathrm{DBP} \geqq 90 \mathrm{mmHg}$ [18].

Fasting blood glucose (FBG) and lipids were measured by Roche $\mathrm{D} / \mathrm{P} / \mathrm{P}$ modular analysis system using enzymatic method. Any kind of the abnormal lipid profiles was defined as dyslipidemia according to the World Health Organization (WHO) criteria thus hypertriglyceridemia (TG $>1.7 \mathrm{mmol} / \mathrm{L}$ ), hypercholesterolemia (TC > $5.2 \mathrm{mmol} / \mathrm{L}$ ), low HDL-C (HDL-C $<0.9 \mathrm{mmol} / \mathrm{L})$, high LDL-C (LDL$\mathrm{C}>3.5 \mathrm{mmol} / \mathrm{L})$, and high TC/HDL-C ratio $(>5)$ [19]. The ratios of TC/HDL-C and AIP were calculated. The ratio $\log$ (TG/HDL-C), which is called AIP, was defined abnormal when $>0.1[20]$.

\section{Statistical analysis}

All analyses were performed by using SPSS version 18.0 software. Continuous variables were described as mean and standard deviation (SD) or median and interquartile range (IQR). Chi-square test was used to test for the difference between categorical variables, whereas the difference between continuous variables was analyzed using the one way ANOVA as appropriate. Pearson's correlation coefficient was used to assess the correlations between AIP and clinical parameters. Univariable linear regression (enter) was performed to identify variables predictive of AIP. All variables with $p$-values $<0.1$ were included in a multivariable linear regression model to examine the potential determinants. A two-tailed $p$-value less than 0.05 was considered statistically significant.

\section{Results}

During the study period, 100 cases of the no-HIV control group, $110 \mathrm{AHI}$ and $110 \mathrm{CHI}$ patients were enrolled. Demographic and clinical characteristics of the study population were summarized in Table 1 . The mean age of AHI group, $\mathrm{CHI}$ group and no-HIV control group were $31.5 \pm 8.6,33.8 \pm 6.2$ and $32.2 \pm 9.0$ respectively. There were no statistically significant differences between the three groups in terms of age, height, weight, BMI, SBP, DBP and proportion of smoking, drinking, hypertension. The mean FBG of the $\mathrm{CHI}$ group was statistically higher than that of the no-HIV control group and the AHI group $(p<0.05)$. Compared with the CHI group, the AHI group had shorter estimated infection time $[65.0(38.5-106.0)$ days vs. $631.0(133.0-1135.0)$ days, $p<0.001]$ and higher CD4 cell counts [404.0 (281.5531.5) cell/ $\mu \mathrm{l}$ vs. $173.0(113.3-243.2)$ cell $/ \mu \mathrm{l}, p<0.001]$. The viral load level between AHI and CHI groups had no statistically difference.

The median value and abnormal proportion of TC, LDL-C of the no-HIV control group were higher than the other two groups (Table 2 and Fig. 1). The no-HIV control group had the highest level of HDL-C and the abnormal proportion of HDL-C of the no-HIV control group was lower than the other two groups. We found

Table 1 Demographic and clinical characteristics of the no-HIV and $\mathrm{AHI}$ and $\mathrm{CHI}$ participants

\begin{tabular}{|c|c|c|c|}
\hline Variables & $\begin{array}{l}\text { No-HIV } \\
(n=100)\end{array}$ & $\begin{array}{l}\mathrm{AHI} \\
(n=110)\end{array}$ & $\begin{array}{l}\mathrm{CHI} \\
(n=110)\end{array}$ \\
\hline Age (years) & $32.2 \pm 9.0$ & $31.5 \pm 8.6$ & $33.8 \pm 6.2$ \\
\hline Height (cm) & $174.0 \pm 5.1$ & $173.9 \pm 4.6$ & $174.5 \pm 6.0$ \\
\hline Weight (kg) & $65.9 \pm 11.4$ & $63.9 \pm 8.5$ & $66.1 \pm 10.9$ \\
\hline $\mathrm{BMI}\left(\mathrm{kg} / \mathrm{m}^{2}\right)$ & $21.8 \pm 3.6$ & $21.1 \pm 2.6$ & $21.7 \pm 3.4$ \\
\hline History of smoking, $n$ (\%) & $38(38.0)$ & $29(26.4)$ & 37 (33.6) \\
\hline History of alcohol, n (\%) & $45(45.0)$ & $44(40.0)$ & $52(47.3)$ \\
\hline $\mathrm{SBP}(\mathrm{mmHg})$ & $120.0(114.6-122.7)$ & $114.5(112.0-120.0)$ & $120.0(116.0-126.1)$ \\
\hline DBP $(\mathrm{mmHg})$ & $80.0(79.0-84.2)$ & $76.0(72.0-78.2)$ & $83.6(79.1-88.0)$ \\
\hline Hypertension, n (\%) & $17(17.0)$ & $10(9.1)$ & $19(17.3)$ \\
\hline FBG (mmol/L) & $4.59(4.21-5.01)$ & $4.88(4.47-5.27)$ & $5.13(4.76-5.53)^{a}$ \\
\hline Estimated infection (days) & NA & $65.0(38.5-106.0)^{b}$ & $631.0(133.0-1135.0)$ \\
\hline CD4 cell count (cells/mm³) & NA & $404.0(281.5-531.5)^{b}$ & $173.0(113.3-243.2)$ \\
\hline $\begin{array}{l}\text { HIV RNA } \\
(\log 10 \text { copies/ml) }\end{array}$ & NA & $4.83(4.43-5.27)$ & $4.66(4.27-4.88)$ \\
\hline
\end{tabular}

No-HIV HIV negative control, $A H I$ acute HIV infection group, $C H I$ chronic HIV infection group, $n$ indicates the number of participants, $B M I$ body mass index, SBP brachial systolic blood pressure, DBP brachial diastolic blood pressure, FBG fasting blood glucose

Data are expressed as mean with \pm standard error of mean, geometric mean with $5^{\text {th }}$ and $95^{\text {th }}$ percentile intervals, $n$ or $\%$ of $n$

NA None applicable

${ }^{\mathrm{a}} p$ value $<0.05$ between $\mathrm{CHI}$ and $\mathrm{AHI}, \mathrm{CHI}$ and no-HIV

${ }^{\mathrm{b}} p$ value $<0.05$ between $\mathrm{AHI}$ and $\mathrm{CHI}$ 
Table 2 Lipid profiles and AIP of the no-HIV, AHI and CHI participants

\begin{tabular}{llll}
\hline Variables & $\begin{array}{l}\text { No-HIV } \\
(n=100)\end{array}$ & $\begin{array}{l}\text { AHI } \\
(n=110)\end{array}$ & $\begin{array}{l}\text { CHI } \\
(n=110)\end{array}$ \\
\hline TG $(\mathrm{mmol} / \mathrm{L})$ & $1.17(0.76-1.67)$ & $1.11(0.89-1.52)$ & $1.06(0.79-1.42)$ \\
TC $(\mathrm{mmol} / \mathrm{L})$ & $4.49 \pm 0.91^{\mathrm{a}}$ & $3.90 \pm 0.73$ & $3.72 \pm 0.74$ \\
HDL-C $(\mathrm{mmol} / \mathrm{L})$ & $1.19 \pm 0.29^{\mathrm{a}}$ & $1.00 \pm 0.25$ & $1.01 \pm 0.30$ \\
LDL-C (mmol/L) & $2.75 \pm 0.78^{\mathrm{a}}$ & $2.11 \pm 0.57$ & $2.22 \pm 0.58$ \\
TC/HDL-C & $3.79(3.18-4.54)$ & $3.95(3.45-4.57)$ & $3.67(3.19-4.29)$ \\
Hypertriglyceridemia, $n(\%)$ & $23(23.0)$ & $17(15.5)$ & $22(20.0)$ \\
Hypercholesterolemia, $n(\%)$ & $21(21.0)^{\mathrm{a}}$ & $7(6.4)$ & $3(2.7)$ \\
Low HDL-C, $n$ (\%) & $17(17.0)^{\mathrm{a}}$ & $37(33.6)$ & $44(40.0)$ \\
High LDL-C, $n$ (\%) & $16(16.0)^{\mathrm{a}}$ & $2(1.8)$ & $2(1.8)$ \\
High TC/HDL-C ratio, $n(\%)$ & $16(16.0)$ & $16(14.5)$ & $15(13.6)$ \\
Dyslipidemia, $n$ (\%) & $44(44.0)$ & $51(46.4)$ & $52(47.3)$ \\
AIP & $-0.04(-0.21-0.22)$ & $0.08(-0.05-0.20)^{\mathrm{b}}$ & $0.03(-0.17-0.23)$ \\
AlP $>0.1, n$ (\%) & $38(38.0)$ & $51(46.4)$ & $48(43.6)$ \\
\hline
\end{tabular}

No-HIV HIV negative control, $A H I$ acute HIV infection group, $C H I$ chronic HIV infection group, TG triglycerides, TC total cholesterol, HDL-C high-density lipoprotein cholesterol, $L D L-C$ low-density lipoprotein cholesterol, AIP the atherogenic index of plasma

${ }^{\mathrm{a}} p$ value $<0.05$ between no-HIV and AHI, no-HIV and $\mathrm{CHI}$

${ }^{\mathrm{b}} p$ value $<0.05$ between no-HIV and $\mathrm{AHI}$

similar values of TG, TC/HDL-C, proportion of hypertriglyceridemia, high TC/HDL-C, and dyslipidemia for the three groups. Compared with the no-HIV control group, the AHI group had higher AIP score [0.08 $(-0.05-0.20)$ vs. $-0.04 \quad(-0.21-0.22), p=0.039]$. There was no difference in the proportion of abnormal AIP of the three groups.

Using Pearson's correlation coefficient, AIP was positively correlated with TC $(p=0.009)$, LDL-C $(p=0.014)$, weight $(p=0.027)$, BMI $(p=0.018)$, DBP $(p=0.045)$ in the no-HIV group (Table 3 , Model 1 ). HIV specific subanalysis was performed in 220 cases of HIV infected patients (AHI group and CHI group), we found that weight $(p=0.001)$, BMI $(p<0.001)$ and HIV RNA $(p=0.029)$ were positively correlated with AIP (Table 3 , Model 2).

Multiple linear regression analysis was carried out to determine the significant predictors of AIP in different groups (Table 4). In no-HIV control group, AIP was associated with TG and TC positively $(\beta=0.245 \pm$ 0.013, $p<0.001 ; \beta=0.039 \pm 0.013, p=0.003)$ and correlated with HDL-C inversely $(\beta=-0.413 \pm 0.041, p<0.001)$. In the AHI group, significant correlation was noticed between AIP and TG $(\beta=0.353 \pm 0.010, p<0.001)$, HDL-C ( $\beta=-0.417 \pm 0.018, p<0.001)$. In the $\mathrm{CHI}$ group we found that TG $(\beta=0.214 \pm 0.018, p<0.001)$, TC $(\beta=0.138 \pm$ $0.049, p=0.006)$ and LDL-C $(\beta=0.100 \pm 0.048, p=0.040)$ were positively correlated with AIP and significant inversely correlation was noticed between AIP and HDL-C ( $\beta=-0.638 \pm 0.066, p<0.001)$. In total groups, AIP was associated with AHI and TG positively $(\beta=0.029 \pm 0.012$, $p=0.015 ; \beta=0.273 \pm 0.009, p<0.001)$ and correlated with HDL-C inversely $(\beta=-0.444 \pm 0.023, p<0.001)$.

\section{Discussion}

Our observational study comprehensively compared the lipid levels and AIP among ART-naïve MSM AHI and

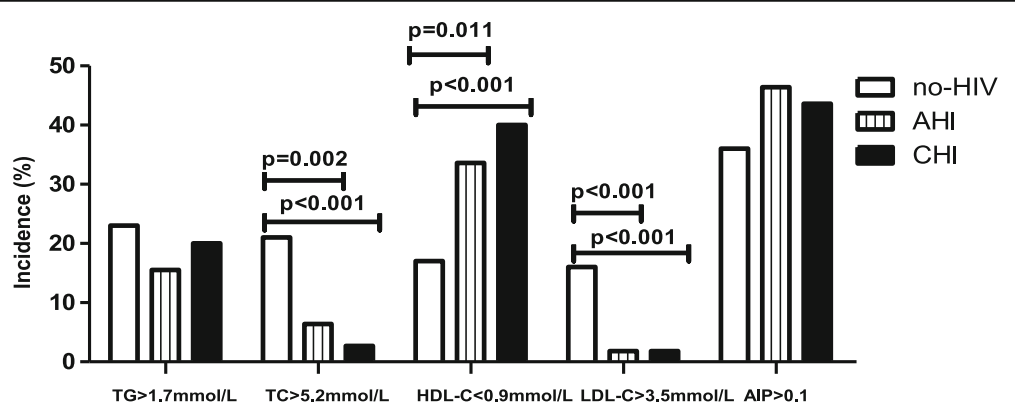

Fig. 1 Incidence of undesirable lipid concentrations among the no-HIV, AHI and CHI group. No-HIV, HIV negative control; AHI, acute HIV infection group; $\mathrm{CHI}$, chronic HIV infection group; TG, triglycerides; TC, total cholesterol; HDL-C, high-density lipoprotein cholesterol; LDL-C, low-density lipoprotein cholesterol; AIP, the atherogenic index of plasma 
Table 3 Pearson correlation coefficients between AIP and clinical and laboratory factors in the no-HIV group (Model 1), and in the HIV group (Model 2)

\begin{tabular}{|c|c|c|c|c|}
\hline \multirow[b]{2}{*}{ Factors } & \multicolumn{2}{|c|}{ Model 1} & \multicolumn{2}{|c|}{ Model $2^{*}$} \\
\hline & $\mathrm{R}$ & $P$ & $\mathrm{R}$ & $P$ \\
\hline $\mathrm{TG}(\mathrm{mmol} / \mathrm{l})$ & 0.915 & $<0.001$ & 0.843 & $<0.001$ \\
\hline $\mathrm{TC}(\mathrm{mmol} / \mathrm{l})$ & 0.258 & 0.009 & -0.015 & 0.821 \\
\hline $\mathrm{HDL}-\mathrm{C}(\mathrm{mmol} / \mathrm{l})$ & -0.680 & $<0.001$ & -0.653 & $<0.001$ \\
\hline LDL-C (mmol/l) & 0.245 & 0.014 & 0.021 & 0.751 \\
\hline FBG (mmol/l) & 0.086 & 0.397 & 0.049 & 0.473 \\
\hline Age (years) & 0.172 & 0.087 & 0.124 & 0.066 \\
\hline Height (cm) & 0.002 & 0.987 & 0.001 & 0.990 \\
\hline Weight (kg) & 0.221 & 0.027 & 0.219 & 0.001 \\
\hline $\mathrm{BMI}\left(\mathrm{kg} / \mathrm{m}^{2}\right)$ & 0.236 & 0.018 & 0.233 & $<0.001$ \\
\hline $\mathrm{SBP}(\mathrm{mmHg})$ & 0.155 & 0.123 & 0.095 & 0.162 \\
\hline $\mathrm{DBP}(\mathrm{mmHg})$ & 0.201 & 0.045 & 0.118 & 0.082 \\
\hline CD4 cell count (cells/mm³) & - & - & -0.063 & 0.364 \\
\hline $\begin{array}{l}\text { HIV RNA } \\
\text { (log10 copies/ml) }\end{array}$ & - & - & 0.151 & 0.029 \\
\hline
\end{tabular}

Model 2*, AHI and $\mathrm{CHI}$ patients were all included

TG triglycerides, TC total cholesterol, HDL-C high-density lipoprotein cholesterol, $L D L-C$ low-density lipoprotein cholesterol, $F B G$ fasting blood glucose, $B M I$ body mass index, SBP brachial systolic blood pressure, $D B P$ brachial diastolic blood pressure
CHI patients with a well-matched HIV negative MSM control group in China. Our study revealed that low levels of TC, HDL-C and LDL-C occurred in both AHI and $\mathrm{CHI}$ groups. High levels of AIP were prevalent during the early stages of HIV-1 infection. The level of TG, the TC/HDL-C ratio and proportion of dyslipidemia were, however, similar in all groups. The AIP correlated with TC, LDL-C, weight, BMI and DBP in MSM control group and correlated with weight, BMI and HIV RNA in the HIV infection group. The significant predictors of AIP were TG, HDL-C and acute HIV infection status.

Our results were similar with other studies which documented significantly lower levels of TC, HDL-C and LDL-C cholesterol in treatment-naïve HIV-infected individuals relative to seronegative controls [21, 22]. Among all the lipid parameters in treatment-naïve HIV-infected patients, TG appeared to have an inconsistent report. In our study, we found that the levels of TG between the HIV infection group and the control group had no statistically significant differences. This result was similar as a previous study [21]. However, Nguemaim NF and Daniyam CA demonstrated that HIV-infected patients had significantly lower TC, HDL-C but higher levels of TG $[22,23]$. A possible explanation for the TG difference may be the differed degrees of immunosuppression of the HIV infection patients. A study conducted in Nigeria showed that the TG levels were reversely correlated with CD4 counts and positively correlated with

Table 4 Factors correlated with AIP after controlling for potential confounders

\begin{tabular}{|c|c|c|c|c|c|c|c|c|}
\hline & \multicolumn{2}{|l|}{ No-HIV } & \multicolumn{2}{|l|}{$\mathrm{AHI}$} & \multicolumn{2}{|l|}{$\mathrm{CHI}$} & \multicolumn{2}{|l|}{ Total* $^{*}$} \\
\hline & $\beta \pm S E$ & $p$ & $\beta \pm S E$ & $p$ & $\beta \pm S E$ & $p$ & $\beta \pm S E$ & $p$ \\
\hline AHI versus HIV-negative & - & - & - & - & - & - & $0.029 \pm 0.012$ & 0.015 \\
\hline $\mathrm{CHI}$ versus HIV-negative & - & - & - & - & - & - & - & - \\
\hline Age (years) & $0.001 \pm 0.001$ & 0.322 & $-0.001 \pm 0.001$ & 0.209 & $-0.001 \pm 0.002$ & 0.747 & $-0.001 \pm .001$ & 0.343 \\
\hline Smoker versus nonsmoker & $-0.004 \pm 0.022$ & 0.841 & $0.009 \pm 0.010$ & 0.374 & $0.020 \pm 0.022$ & 0.369 & $0.013 \pm 0.013$ & 0.319 \\
\hline Drinker versus nondrinker & $0.009 \pm 0.020$ & 0.653 & $-0.012 \pm 0.009$ & 0.177 & $-0.033 \pm 0.022$ & 0.137 & $-0.011 \pm 0.012$ & 0.342 \\
\hline $\mathrm{BMI}\left(\mathrm{kg} / \mathrm{m}^{2}\right)$ & $-0.001 \pm 0.003$ & 0.690 & $0.001 \pm 0.002$ & 0.520 & $0.000 \pm 0.003$ & 0.963 & $0.003 \pm 0.002$ & 0.139 \\
\hline $\mathrm{TG}(\mathrm{mmol} / \mathrm{L})$ & $0.245 \pm 0.013$ & $<0.001$ & $0.353 \pm 0.010$ & $<0.001$ & $0.214 \pm 0.018$ & $<0.001$ & $0.273 \pm 0.009$ & $<0.001$ \\
\hline $\mathrm{TC}(\mathrm{mmol} / \mathrm{L})$ & $0.039 \pm 0.013$ & 0.003 & - & - & $0.138 \pm 0.049$ & 0.006 & - & - \\
\hline $\mathrm{HDL}-\mathrm{C}(\mathrm{mmol} / \mathrm{L})$ & $-0.413 \pm 0.041$ & $<0.001$ & $-0.417 \pm 0.018$ & $<0.001$ & $-0.638 \pm 0.066$ & $<0.001$ & $-0.444 \pm 0.023$ & $<0.001$ \\
\hline LDL-C (mmol/L) & - & - & - & - & $0.100 \pm 0.048$ & 0.040 & - & - \\
\hline $\mathrm{FBG}(\mathrm{mmol} / \mathrm{L})$ & - & - & - & - & - & - & - & - \\
\hline $\mathrm{SBP}(\mathrm{mmHg})$ & - & - & - & - & - & - & - & - \\
\hline $\mathrm{DBP}(\mathrm{mmHg})$ & - & - & - & - & - & - & - & - \\
\hline CD4 cell count (cells/mm3) & - & - & - & - & - & - & - & - \\
\hline $\begin{array}{l}\text { HIV RNA } \\
\text { (log10 copies/ml) }\end{array}$ & - & - & - & - & - & - & - & - \\
\hline
\end{tabular}

No-HIV HIV negative control, $A H I$ acute HIV infection group, CHI chronic HIV infection group, Total*, no-HIV, AHI and CHI participants were all included; BMI body mass index, TG triglycerides, TC total cholesterol, HDL-c high-density lipoprotein cholesterol, LDL-C low-density lipoprotein cholesterol, FBG fasting blood glucose, SBP brachial systolic blood pressure, DBP brachial diastolic blood pressure

The $\beta$ values are the multivariate regression unstandardized coefficients

$S E$, standard error of mean 
viral load [11]. The HIV infected participants in our study had a better immune status as reflected by a median CD4 cell count of $404.0(281.5-531.5)$ cell/ $\mu \mathrm{l}$ in the AHI group and 173.0 (104.3-243.2) in the CHI group compared to previous studies. Increased TG tends to occur with profound immunosuppression. HIV infection induced a typically early decrease of TC first, followed by HDL-C and LDL-C, and TG increase last. These lipids alterations associated with specific changes in immune function [11, 21].

This was the first study that we knew of to report data on AIP in the acute HIV-infected individuals. The use of the AIP as an index of dyslipidaemia showed that the AHI patients were at higher risk of atherosclerosis compared with the MSM control group despite their low levels of TC and LDL-C. In our study, the AIP values between $\mathrm{CHI}$ group and MSM control group were not statistically different. Cajetan C. Onyedum's study showed that higher AIP was frequent in ART-naïve CHI patients [24]. However, this study did not have a control group, and most of enrolled patients were female. Significantly more females than males had dyslipidemia, which may contribute to higher AIP value $[11,25]$. Our result suggested that the patients in the early HIV infection stage should be monitored lipids frequently. China is the largest developing country and the economy develops imbalanced. Medical resource backwardness exists in remote areas. In resource limited setting of China, the AIP is a simple and practical ratio to estimate the risk of atherosclerosis and cardiovascular disease.

In terms of the relationship between AIP and other factors, our study showed that the AIP was closely related with factors such as TC, LDL-C, weight, BMI and DBP in the MSM group. We also demonstrated a relationship between AIP and HIV viral load level in the HIV infection group apart from weight and BMI. Those who had higher level of HIV RNA had a higher atherogenic risk profile. This is consistent with the previously reported studies which showed HDL-C was negatively correlated with viral load and the TG levels was positively correlated with viral load on the contrary $[11,22,26]$. These studies also demonstrated AIP or lipids parameters correlated with immunologic status of HIV infected people. In our study we did not find the association between AIP and CD4 cell counts of HIV infected people, further researches about this should be performed.

The result of multivariable linear regression demonstrated that acute HIV infection was associated with higher AIP after controlling for potential confounders. AHI patients had higher level of HIV viral load which may result in the increase of AIP. This may have reflected a direct relationship between viral replication and chronic inflammation caused by cytokine. The continuous viral replication induces inflammation and cytokine secretion such as IFN- $\alpha$, which was believed to make a contribution to increased TG level [27]. Janet Lo's study showed that the high magnitude of viremia characteristic of AHI impaired cholesterol efflux from macrophages, which could be improved with suppression of viral replication by ART [13]. We speculate that suppressing viremia may reduce atherosclerotic risk in early stage of HIV infection and prospective analyses with larger sample size should be performed to confirm this. An urgent need exists for earlier dyslipidemia diagnosis and better access to treatment in China.

Strengths of our study include the well matched HIV negative MSM control group. Most studies used individuals from the general population as the healthy controls, who might have lifestyles and related risk factors differ from those of the HIV infected patients. Therefore, to precisely evaluate the effect of HIV infection on lipids metabolism and AIP among MSM, it is necessary to use HIV-negative MSM population as the control group. Moreover, due to the rising cost and the relative low HIV testing rate, screening for acute HIV infection is difficult in China. In this study, acute HIV infection patients were enrolled based on rigorous criteria.

There were several limitations in our study. First of all, the sample size of HIV infection group was too small to show a real difference and detect significant associations between AIP and other risk factors. Secondly, all the participants were MSM, our conclusion cannot be applied to other populations. Thirdly, due to the crosssectional design, we could not infer causal relationships and assess the kinetics of AIP changes.

Despite these limitations, to our knowledge, this is the first study that investigated AIP among ART-naivve MSM patients in China and will no doubt stimulate more research in this field. As a convenient and cheap method to predict cardiovascular disease risk, AIP is recommended in China. Life style modification and prompt treatment are needed to prevent lipids metabolism dysfunction. Longitudinal studies are needed to evaluate the risk of atherosclerosis and cardiovascular events over time.

\section{Conclusions}

Our study revealed that low levels of TC, HDL-C, LDL$\mathrm{C}$ and high level of AIP were prevalent during the early stages of HIV-1 infection. The AIP correlated with TC, LDL-C, weight, BMI and DBP in MSM control group and correlated with weight, BMI and HIV RNA in the HIV infection group. The significant predictors of AIP were TG, HDL-C and acute HIV infection status. Life style modification and prompt treatment are needed to prevent lipids metabolism dysfunction. 


\section{Acknowledgements}

We thank Jing Wang, Ying He, Jing Ma and Rui Li from the Key Laboratory of AIDS Immunology of National Health and Family Planning Commission, Department of Laboratory Medicine, The First Affiliated Hospital, China Medical University for assistance with blood collection and scheduling patient appointments.

\section{Funding}

This study was supported by the the Mega Projects of National Science(2013ZX09303002); Fundamental and clinical medicine closed union platform-clinical evaluation technology platform of anti-HIV and antineoplastic new drugs (YDFZ-2013-5); Project of Technology Department of Liaoning Province for the 12th 5-Year Plan (2013225079); National key technologies R\&D program of China (2012BAI37B01).

The authors have no other relevant affiliations or financial involvement with any organization or entity with a financial interest in or financial conflict with the subject matter or materials discussed in the manuscript apart from those disclosed. No writing assistance was utilized in the production of this manuscript.

\section{Authors' contributions}

QW and HS planned the study protocol. QW, HD, JL, JK and XL carried out the study and drafted the manuscript. JX, WG and YJ coordinated the research and revised the paper. HS revised the final version of the manuscript. All authors approved the final manuscript.

\section{Competing interests}

The authors declare no competing interests.

\section{Consent for publication}

Not applicable.

\section{Ethics approval and consent to participate}

The study was approved by the Ethics Committee of the First Affiliated Hospital of China Medical University and the Beijing You'An Hospital. All participants provided written informed consent before attending this study.

Received: 7 February 2016 Accepted: 27 July 2016

Published online: 06 September 2016

\section{References}

1. Heath KV, Hogg RS, Chan KJ, Harris M, Montessori V, O'Shaughnessy MV, Montanera JS. Lipodystrophy-associated morphological, cholesterol and triglyceride abnormalities in a population-based HIV/AIDS treatment database. AIDS. 2001;15:231-9.

2. Husain NE, Ahmed MH. Managing dyslipidemia in HIV/AIDS patients: challenges and solutions. HIV AIDS (AuckI). 2014; doi:10.2147/HIV.S46028.

3. Myerson M. Lipid management in human immunodeficiency virus. Endocrinol Metab Clin North Am. 2016:45:141-69.

4. Grunfeld C, Delaney JA, Wanke C, Currier JS, Scherzer R, Biggs ML, Tien PC, Shlipak MG, Sidney S, Polak JF, O'Leary D, Bacchetti P, Kronmal RA. Preclinical atherosclerosis due to HIV infection: carotid intima-medial thickness measurements from the FRAM study. AIDS. 2009;23:1841-9.

5. Carr A, Samaras K, Burton S, Law M, Freund J, Chisholm DJ, Cooper DA. A syndrome of peripheral lipodystrophy, hyperlipidaemia and insulin resistance in patients receiving HIV protease inhibitors. AIDS. 1998;12:F51-8.

6. DAD Study Group, Friis-Møller N, Reiss P, Sabin CA, Weber R, Monforte A, El-Sadr W, Thiébaut R, De Wit S, Kirk O, Fontas E, Law MG, Phillips A, Lundgren JD. Class of antiretroviral drugs and the risk of myocardial infarction. N Engl J Med. 2007;356:1723-35.

7. Sension M, Deckx H. Lipid metabolism and lipodystrophy in HIV-1-infected patients: the role played by nonnucleoside reverse transcriptase inhibitors. AIDS Rev. 2015;17:21-36.

8. Abebe M, Kinde S, Belay G, Gebreegziabxier A, Challa F, Gebeyehu T, Nigussie P, Tegbaru B. Antiretroviral treatment associated hyperglycemia and dyslipidemia among HIV infected patients at Burayu Health Center, Addis Ababa, Ethiopia: a cross-sectional comparative study. BMC Res Notes. 2014;7:380.

9. Siegel $M O$, Borkowska $A G$, Dubrovsky $L$, Roth $M$, Welti R, Roberts $A D$, Parenti DM, Simon GL, Sviridov D, Simmens S, Bukrinsky M, Fitzgerald ML. HIV infection induces structural and functional changes in high density lipoproteins. Atherosclerosis. 2015;243:19-29.
10. Kanjanavanit S, Puthanakit T, Vibol U, Kosalaraksa P, Hansudewechakul R, Ngampiyasakul C, Wongsawat J, Luesomboon W, Wongsabut J, Mahanontharit A, Suwanlerk T, Saphonn V, Ananworanich J, Ruxrungtham K, PREDICT study group. High prevalence of lipid abnormalities among antiretroviral-naive HIV-infected Asian children with mild-to-moderate immunosuppression. Antivir Ther. 2011;16:1351-5.

11. Kuti MA, Adesina OA, Awolude OA, Ogunbosi BO, Fayemiwo SA, Akinyemi JO, Adetunji AA, Irabor AE, Odaibo GN, Prosper O, Taiwo BO, Olaleye D, Murphy RL, Kanki P, Adewole IF. Dyslipidemia in ART-Naive HIV-Infected Persons in Nigeria-Implications for Care. J Int Assoc Provid AIDS Care. 2015;14:355-9.

12. So-Armah KA, Chang J, Alcorn C, Lo Re V, Baker JV, Tracy R, Butt AA, Agan BK, Rimland D, Gibert CL, Goetz MB, Oursler KK, Rodriguez-Barradas MC, Kuller LH, Brown ST, Stein JH, Skanderson M, Justice AC, Freiberg MS. HIV infection, antiretroviral therapy initiation and longitudinal changes in biomarkers of organ function. Curr HIV Res. 2014;12:50-9.

13. Lo J, Rosenberg ES, Fitzgerald ML, Bazner SB, Ihenachor EJ, Hawxhurst V Borkowska AH, Wei J, Zimmerman CO, Burdo TH, Williams KC, Freeman MW, Grinspoon SK. High-density lipoprotein-mediated cholesterol efflux capacity is improved by treatment with antiretroviral therapy in acute human immunodeficiency virus infection. Open Forum Infect Dis. 2014; doi:10.1093/ofid/ofu108

14. Dobiasova M, Frohlich J. The plasma parameter log (TG/HDL-C) as an atherogenic index: correlation with lipoprotein particle size and esterification rate in apoB-lipoprotein-depleted plasma (FER(HDL)). Clin Biochem. 2001:34:583-8.

15. Lu L, Jia M, Ma Y, Yang L, Chen Z, Ho DD, Jiang $Y$, Zhang $L$. The changing face of HIV in China. Nature. 2008;455:609-11.

16. Xu JJ, Qian HZ, Chu ZX, Zhang J, Hu QH, Jiang YJ, Geng WQ, Zhang CM, Shang $\mathrm{H}$. Recreational drug use among Chinese men who have sex with men: a risky combination with unprotected sex for acquiring HIV infection. Biomed Res Int. 2014: doi:10.1155/2014/725361.

17. Stall R, Paul JP, Greenwood G, Pollack LM, Bein E, Crosby GM, Mills TC, Binson D, Coates TJ, Catania JA. Alcohol use, drug use and alcohol-related problems among men who have sex with men: the Urban Men's Health Study. Addiction. 2001;96:1589-601.

18. Mancia G, De Backer G, Dominiczak A, Cifkova R, Fagard R, Germano G, Grassi G, Heagerty AM, Kjeldsen SE, Laurent S, Narkiewicz K, Ruilope L, Rynkiewicz A, Schmieder RE, Boudier HA, Zanchetti A, Vahanian A, Camm J, De Caterina R, Dean V, Dickstein K, Filippatos G, Funck-Brentano C, Hellemans I, Kristensen SD, McGregor K, Sechtem U, Silber S, Tendera M, Widimsky P, Zamorano JL, Erdine S, Kiowski W, Agabiti-Rosei E, Ambrosioni E, Lindholm LH, Viigimaa M, Adamopoulos S, Agabiti-Rosei E, Ambrosioni E, Bertomeu V, Clement D, Erdine S, Farsang C, Gaita D, Lip G, Mallion JM, Manolis AJ, Nilsson PM, O'Brien E, Ponikowski P, Redon J, Ruschitzka F, Tamargo J, van Zwieten P, Waeber B, Williams B, Management of Arterial Hypertension of the European Society of Hypertension, European Society of Cardiology. 2007 Guidelines for the Management of Arterial Hypertension: The Task Force for the Management of Arterial Hypertension of the European Society of Hypertension (ESH) and of the European Society of Cardiology (ESC). J Hypertens. 2007;25:1105-87.

19. Cardiovascular disease risk factors: new areas for research. Report of a WHO Scientific Group. World Health Organ Tech rep ser. 1994; 841:1-53.

20. Dobiasova M. AlP-atherogenic index of plasma as a significant predictor of cardiovascular risk: from research to practice. Vnitr Lek. 2006;52:64-71.

21. Shor-Posner G, Basit A, Lu Y, Cabrejos C, Chang J, Fletcher M, ManteroAtienza E, Baum MK. Hypocholesterolemia is associated with immune dysfunction in early human immunodeficiency virus-1 infection. Am J Med. 1993;94:515-9.

22. Nguemaïm NF, Mbuagbaw J, Nkoa T, Alemnji G, Této G, Fanhi TC, Asonganyi T, Samé-Ekobo A. Serum lipid profile in highly active antiretroviral therapy-naive HIV-infected patients in Cameroon: a casecontrol study. HIV Med. 2010;11:353-9.

23. Daniyam C, Iroezindu M. Lipid profile of anti-retroviral treatment-naive hiv-infected patients in Jos, Nigeria. Ann Med Health Sci Res. 2013;3:26-30.

24. Onyedum CC, Young EE, Iroezindu MO, Chukwuka CJ, Nwagha UI. Atherogenic index of plasma in highly active antiretroviral therapy-naive patients with human immunodeficiency virus infection in Southeast Nigeria. Indian J Endocrinol Metab. 2014;18:631-6.

25. Zea-Robles AC, Leon-Ariza HH, Botero-Rosas DA, Afanador-Castaneda HD, Pinzon-Bravo LA. University students' cardiovascular risk factors and their 
relationship with body composition. Rev Salud Publica (Bogota). 2014;16:505-15.

26. El-Sadr WM, Mullin CM, Carr A, Gibert C, Rappoport C, Visnegarwala F, Grunfeld C, Raghavan SS. Effects of HIV disease on lipid, glucose and insulin levels: results from a large antiretroviral-naive cohort. HIV Med. 2005;6:114-21.

27. Grunfeld C, Pang M, Doerrler W, Shigenaga JK, Jensen P, Feingold KR. Lipids, lipoproteins, triglyceride clearance, and cytokines in human immunodeficiency virus infection and the acquired immunodeficiency syndrome. J Clin Endocrinol Metab. 1992;74:1045-52

Submit your next manuscript to BioMed Central and we will help you at every step:

- We accept pre-submission inquiries

- Our selector tool helps you to find the most relevant journal

- We provide round the clock customer support

- Convenient online submission

- Thorough peer review

- Inclusion in PubMed and all major indexing services

- Maximum visibility for your research

Submit your manuscript at www.biomedcentral.com/submit
Biomed Central 